\title{
How Reflective are Lesson Study Discussion Sessions? Developing an Instrument to Analyze Collective Reflection
}

\author{
Yumiko Ono $^{1, *}$, Kensuke Chikamori ${ }^{1}$ \& John M. Rogan ${ }^{2}$ \\ ${ }^{1}$ Center for International Cooperation in Teacher Education and Training, Naruto University \\ of Education, Tokushima, 772-8502, Japan \\ ${ }^{2}$ University of KwaZulu-Natal, Edgewood Campus, Pinetown 3610, South Africa \\ *Corresponding author: E-mail: onoy@naruto-u.ac.jp
}

Received: June 12, 2013 Accepted: July 6, 2013 Published: July 22, 2013

doi:10.5296/ije.v5i3.3847ＵRL: http://dx.doi.org/10.5296/ije.v5i3.3847

\begin{abstract}
The purpose of this paper is to report on the development of an instrument designed to measure the topics and levels of reflection that occur during the post-lesson discussions of the lesson study cycle. The main elements of lesson study are:

- Collaborative design of lessons or units of study

- Execution of the design with observation

- Reflection on the product with a view to its improvement

It is seen as a cyclical process in that the reflection stage leads to a renewed collaboration on the design of an improved lesson or unit. Hence the quality of the reflection stage is seen as crucial to the success of the enterprise.

The literature on definitions of reflection and on levels and topics of reflection was reviewed to provide a starting point for the development of the instrument. Initial categories of both levels and topics of reflection were developed by analyzing transcripts of post-lesson discussion sessions using a grounded approach. These initial categories were then further refined by analyzing some additional post-lesson discussion transcripts. Finally the developed instrument was applied to the transcript of a discussion that occurred in an Indonesian school to establish its usefulness and sensitivity.
\end{abstract}

Keywords: lesson study; post lesson discussion; reflection 


\section{Introduction}

Over the past twenty years the Japan International Cooperation Agency (JICA) has become increasingly active in supporting education in developing countries. As of the end of 2011 it is, or has recently been, active in many African countries including Kenya, Malawi, South Africa, Zambia, as well as Asian countries including Indonesia, Cambodia and the Philippines. Most of these initiatives are geared towards science and mathematics education, and many involve, as part of the initiative, an introduction to lesson study with the goal that it will continue to be practiced in the host country. Lesson study, as a vehicle for professional development and research, has also gained adherents in countries such as the USA, United Kingdom, Sweden, Australia, Hong Kong, China, Singapore, Thailand and others, where it is not promoted by JICA.

The main elements of lesson study are:

- Collaborative design of lessons or units of study

- Execution of the design with observation

- Reflection on the product with a view to its improvement

It is seen as a cyclical process in that the reflection stage leads to a renewed collaboration on the design of an improved lesson or unit. Research on the introduction of lesson study has been carried out in a number of countries, including those listed above. Most of the studies to date have focused on the introduction of lesson study in various contexts, or more generally on broader issues to do with reform. We wish to focus specifically on one aspect of lesson study, the nature and effectiveness of the post-lesson reflection phase. Since the purpose of this reflection session is to improve a lesson or unit for future use, our concern as promoters of this practice in a number of different countries is whether, over time, these discussions become more thoughtful, insightful, and effective in terms of lesson improvement. Unless lesson study is able to show results in terms of better teaching and learning, there is little point in expending the effort and time that it demands. During the past years we have experienced intuitive-based impressions of what constitutes insightful and effective discussion sessions. However, if we wish to claim, for example, that one particular method of promoting lesson study leads to more effective post-lesson discussions, we need to go beyond intuitive impressions and develop a more rigorous method of describing these sessions. The development of such an instrument represents the first step in our research program, and the focus of this article.

\section{Literature Review}

\subsection{Definitions of Reflection}

In an attempt to categorize various meanings that the term reflection might take on, Fendler (2003, p.17) traces four interrelated, but sometimes contradictory, threads: the epistemological foundations of Cartesian rationality, Dewey's works as the authoritative 
voice of progressive education, Schön's (1983) emphasis on professionalism for teachers, and feminist, anti-establishment critiques. Of these, definitions that espouse the Deweyian tradition come closest to capturing the meaning of reflection in lesson study.

As far back as the 1930s, John Dewey regarded reflective thinking as an important aspect of education. According to him, reflective thinking "converts action that is merely appetitive, blind, and impulsive into intelligent action” (1933, p.17). As Fendler (2003, p.17) points out, “... a particular kind of reflective thinking emerged in the early part of this century for very modern reasons: Reflective thinking represented a triumph of reason and science over instinct and impulse." By way of contrast, “Schön's definition of reflection is generally understood to be artistic and practice based as opposed to positivistic and science based" (Fendler, 2003, p.19).

Dewey's writings have inspired a number of definitions of reflection. One example is:

..., reflection in the context of learning is a generic term for those intellectual and affective activities in which individuals engage to explore their experiences in order to lead to new understandings and appreciations. (Boud, Keogh and Walker, 1985, p.19)

This definition regards reflection as an individual activity leading to an enhanced mental or affective state of that person. However, the link between understanding and possible action is not made explicitly.

There are a number of definitions of reflection that move towards satisfying the meaning of the term as used in our lesson study context, where the end goal implies action rather than just understanding. One such example is given by van Woerkom (2003, p. 40).

Reflection is a mental activity aimed at investigating one's own action in a certain situation and involved in a review of the experience, an analysis of causes and effects, and the drawing of conclusions concerning future action.

This definition is more in line with the purpose of our research in that it focuses on the deliberation of a specific action with a view to what might be done differently in the future. However, the focus is still on the individual, both in terms of the action and the reflection.

In the case of lesson study, the reflection is undertaken in a group setting where the potential exists to build on others' concerns, insights, and ideas for future action. In this context, van Manen's notion (1991, p. 510) comes closer to the mark.

Reflection is possible in those moments when we are able to think about our experiences, about what we did or should have done, or what we might do next.

... reflection in the field of education carries the connotation of deliberation, making choices, coming to decisions about alternative courses of action.

He goes on to observe (p. 511):

Even more problematic is the lack of opportunity to reflect thoughtfully with colleagues about the practice and meaning of pedagogical experiences. 
Lesson study provides one way to address this problem of isolation.

We would like to mention one final point made by Boud, Keogh, and Walker (1985). They emphasize that the promotion of quality reflection depends on strengthening "the link between the learning experience and the reflective activity which follows it.” (p. 26) In the case of lesson study, this dictum implies that the reflection session should be immediate, and should be seen by participants to be relevant to their own needs and purposes.

Having explored various notions and definitions of reflection, we now offer our own definition pertaining specifically to our research of lesson study.

Reflection, following the observation of a lesson, is an intellectual activity undertaken in a group setting by means of discussion among participants and observers to explore ways of improving the quality of future student learning, with particular reference to the design of the lesson, the materials used, and the mode of delivery.

In this definition, reflection is embedded in a social context as well as implying action. However, it is important to make explicit aspects that are excluded by this definition. When practiced in Japan, lesson study reflection is not seen as a pathway to personal enlightenment or fulfillment. It is a collaborative effort to improve a product, and hence positivistic, rather than intuitive in nature. Nor does it seek to engage in any form of social reconstruction, or even to reflect on the possible political or social assumptions underlying the curriculum. In Japan, the curriculum is developed by expert committees, and is not subject to challenge or change by teachers. On the other hand, teachers are encouraged to come up with creative and effective ways of implementing this prescribed curriculum.

\subsection{Levels of Reflection}

One prevalent distinction is to define two categories, namely reflection and critical reflection. The latter, according to Mezirow (1998), involves an examination of the assumptions or presuppositions on which judgments are being made or actions designed, while the former does not necessarily challenge any basic assumptions. Hence critical reflection as defined by Mezirow provides one condition for "higher-order" reflection. Fendler (2003, p.21) points out, "Reflection that is purely instrumental or technical, without explicit attention to issues of social justice, is denounced by some critical theorists." In this case higher-order reflection is conditional upon political or social awareness and or action. All technical reflection is assigned to a single lower-order level. However, there are a number of attempts to define levels of reflection that go beyond two-category distinction of reflection and critical reflection, van Manen (1991), and King and Kitchener (1994) providing two such examples.

When reviewing the efforts of a number of researchers to create rubrics to measure levels of reflection in various contexts (see next section) the writings of van Manen seem to have been the most influential. Van Manen (1991, p.512) defines four levels at which reflection might occur:

1. Everyday, common-sense thinking (pre-reflective), partly habitual, partly routinized, partly intuitive. 
2. Limited insight, but verbalized reflections on practical experiences in everyday life.

3. Systematic and sustained reflection on our own and others' experiences with the aim of developing understanding and critical insights into ensuing actions.

4. Reflection on the way we reflect in order to achieve a better grasp of the nature of knowledge and how it can be applied to the understanding of our actions.

The two higher levels are clearly demarcated from the lower two in their primary concern. Reflective activities at the lower levels are experience-oriented, with or without a limited insight on practical experiences. Additionally, level two can be differentiated from the level one by the existence of insight albeit limited. The reflections at the higher two levels are action-oriented with the clear objective of developing understanding and insight, or of achieving a better grasp of the nature of knowledge and its application to the understanding of action. The difference between the levels three and four is in the target of concern. At level three, it would be "our own and others' experience" but at level four the reflection is directed to "the way we reflect". Van Manen defines the levels of reflection according to their orientation (from experience to action) and objectives or outcomes (limited insight, understanding, grasp and way of application).

The work of King and Kitchener (1994) focuses on "reflective judgment" and how this attribute changes with age. Reflective judgments are "based on the evaluation and integration of existing data and theory into a solution about a problem at hand, a solution that can be rationally defended as most plausible or reasonable, taking into account the sets of conditions under which the problem is being studied” (p. 8). They envisage reflective judgment passing through a number of increasingly abstract stages. For example at stage one, knowing is concrete, certain, and based on personal experience. By stage seven, knowledge is abstract, complex, and seen to be the product of reasoned inquiry. The seven stages are grouped into three broader categories; Pre-reflective, Quasi-reflective, and Reflective. Each stage is defined along two dimensions; the view held about the knowledge itself - the degree to which it is believed to be unchallengeable, and secondly the manner in which the belief is justified.

\subsection{Measurement of Levels and Topics of Reflection}

\subsubsection{Measurement of Levels of Reflection}

The earliest of the studies reviewed is that of Goodman (1984). In each of the three levels proposed in this study, the subject of reflection is the teaching experience of pre-service student teachers, without differentiation as to the various kinds of experiences. At the first level the reflection focuses on "techniques needed to reach given objectives" (p. 17). The worth of the objectives themselves is not questioned. At the second level, the focus of reflection is on "the relationship between educational principles and practice" (p. 17). At this level both the techniques and the objectives come under scrutiny. At the third and final level the worth of the objectives and practices are reflected upon in terms of ethical and political norms and values. 
A number of other studies we reviewed are based loosely on the van Manen levels, and like Goodman are based on an undifferentiated student teaching experience. However one notable departure is to define some lower levels as devoid of reflection. Kember et al. (2008), for example, define their first two categories as being non-reflective. The first is termed habitual action - following a routine without much thought. The second level is still routine, but with a level of understanding about the action being performed. At the third level, termed reflection, there are insights based on personal experiences, which go "beyond book theory" (p. 374). At this stage, the experiences would be internalized as well as personalized as knowledge. Finally critical reflection requires a "review of presuppositions from conscious and unconscious prior learning and their consequences” (p. 374). Hatton and Smith (1995) define their first level as purely descriptive, devoid of any reflection. At the second level these descriptions are justified and the existence of alterative viewpoints acknowledged. At the third level, termed dialogic, the reflection is "analytical or/and integrative of factors and perspectives and may recognize inconsistencies in attempting to provide rationale and critique” (p. 49). Critical reflection, the fourth level, "demonstrates an awareness that actions and events are not only located in, and explicable by, reference to multiple perspectives but are located in, and influenced by multiple historical and socio-political contexts” (p. 49). The four levels of Ward and McCotter (2004) and of Suratno and Iskandar (2010) are similar to those of Hatton and Smith.

The Hatton and Smith (1995) study introduces a categorical scheme found in other articles reviewed, that of single versus multiple perspectives. In Ross's (1989) three-level scheme, reflection from a single perspective occurs at level two. Level three requires reflection from multiple perspectives, where instructional decisions are evaluated "in terms of conflicting aims” (p. 26). Galvez-Martin et al. (1998) also use perspective as a criterion for differentiating levels. At the lower levels of their seven-stage scheme they stipulate a single perspective; first that of the student (level 4) and later that of the supervising teacher (level 5). Finally at level seven, reflection from multiple perspectives is called for.

King and Kitchener (1994) introduce two additional criteria in their seven-level reflection scheme. The first is that of the "View of Knowledge". At stage one, knowledge is conceived as absolute and concrete (p. 14). This view of knowledge gradually progresses through the stages becoming more uncertain and subjective, until at stage seven it is conceived as "the outcome of a process of reasonable inquiry" (p. 15). The second criterion is that of justification. This concept progresses from no justification at all to taking into consideration aspects such as "weight of evidence" to an ever-increasing extent.

\subsubsection{Topics of Reflection}

Most of the studies reviewed placed their emphasis on levels of reflection based on the overall experiences of those engaged in the reflection, without attempting to categorize these experiences. There are exceptions to this generalization, thus creating a two-dimensional matrix when measuring levels of reflection. Dinkelman's (2000) study was based on secondary education student teachers, resulting in two specific categories of reflection, issues specific to social studies and issues directed at democratic education. Ross (1989) likewise 
subdivided the overall experience into five categories: Examples of teacher effectiveness; Problems and concerns; Beliefs and experiences; Defining good teaching - basic; and Defining good teaching - general.

Two studies were reviewed that are specifically based on the topics that emerged during the post-lesson reflection phase of the lesson study cycle, Suratno and Iskandar (2010) and Suzuki (2012). The former was undertaken in Indonesia, where JICA has been active in the promotion of lesson study as a form of professional development. The four categories that emerged in their study are: Teachers' teaching; Students' learning; Teaching materials; and Teaching strategies. The study by Suzuki was conducted in Japan, and grouped the reflection into six categories: Simple question and answer; Is the alternative teaching approach better?; What is the best way of teaching X?; Did the children learn what the teacher intended them to?; Did the teacher teach what the children actually learned?; and What did the teacher learn from watching the children learn?

\subsection{Implications}

The studies summarized above influenced our initial attempts at creating an instrument to measure reflection in the context of lesson study. In particular, we were interested in the criteria used to define levels, and in the lower and upper bounds subsequently stipulated. In most of the studies, the criteria for defining levels were implicit rather than explicit. Some appeared to change or mix criteria as they moved from one level to another. However, in broad terms the criteria used mostly likely fit one of the following three Fendler (2003) categories:

- Rationale analysis with the goal of improving teaching and learning;

- Intuitive analysis with the goal of personal transformation;

- Critical analysis with the goal of social reconstruction.

Since our interest lies with the first of these three, we looked more closely at the defined boundaries of these studies. There were four studies in this group, Hatton and Smith (1995), Kember et al. (2008), Suratno and Iskandar (2010), and Ward and McCotter (2004). The first level of each of these studies is commonly defined as non-reflective - mostly a description of an event. Subsequent levels are defined by the inclusion of a greater degree of understanding and insight. The highest levels include the application of theory to the described events or the questioning of assumptions underlying the observed practice.

Most of the studies reviewed defined either three or four levels of reflection. However it was noticeable that the highest level was seldom, if at all, attained when applied in practice. The lesson that we gleaned from these studies was that we needed to develop a more fine-grained approach to the lower levels of reflection, and less stringent criteria for the higher ones. It seems somewhat futile to define "higher-order" levels which remain unattained all the time. Also given the nature of lesson study, we needed to focus less on personal development, as was the case with preservice teachers, and more on lesson improvement.

The question of whether to differentiate the topics of reflection was raised by the studies - 
some did while others did not. When it came to lesson study, we felt it important to examine what was being reflected on as well as the level of reflection. However we realized that there is an interaction between topic and potential reflection levels. For example, reflection on some logistical aspects of a lesson - how worksheets were distributed for example - can hardly attain a higher-order level. On the other hand, reflection on the goals of a lesson, and whether these have been realized can certainly be conducted at higher levels.

\section{Methodology}

We adopted a two-pronged approach in developing the levels and types of reflection in our instrument. On the one hand we took cognizance of the levels proposed in the reviewed studies. However these served only as initial guideposts. We then took a grounded approach by identifying types and levels of reflection in transcripts of a number of post lesson analysis sessions.

Four transcripts were used to identify the topics and levels, selected to provide diversity of settings, but all were based on a science lesson. The four are:

- High school biology lesson by South African participants in a workshop in Japan, and presented in a simulated setting (November 2004).

- Middle school biology lesson in an Indonesia school, presented by a teacher from that school (August 2010).

- Primary school science lesson by Kenyan participants in a workshop in Japan, and presented in a simulated setting (November 2011).

- Primary school science lesson in a Japanese school, presented by a teacher from that school (November 2011).

The first step was to analyze the South African and Indonesian discussions in order to identify initial categories of topics, and levels of reflection within each category. The analysis of the transcripts followed a procedure similar to that followed by Ward and McCotter (2004). We first "fractured" the data by dividing each transcript into segments or "chunks" that expressed a single idea. These segments could consist of an entire paragraph, or be as short as a single sentence or phrase. The segments were then sorted into groups representing specific topics. Non-reflective statements such as the moderator's introductions and appreciations (Thank you Mr. Khosa for making your point so clearly) and statements not dealing with the actual lesson were excluded in this process. The analysis described above resulted in five categories of topics:

- Teaching and learning strategies; Instructional techniques and practices.

- Teacher behavior; teacher characteristics; communication skills.

- Lesson as experienced by students; student learning; student behavior; interaction between students. 
- Achievement of lesson and curriculum objectives (e.g. thinking skills, creativity, conceptual understanding); inconsistency with objectives.

- Logistics; management; planning; use of materials and teaching aids.

Four of the five categories correspond to basic components of classroom teaching: How the teacher teaches, his or her communication skills, how students participate in the lesson, and how the teacher uses materials according to a plan. The other category addresses how the lesson and curriculum objectives are achieved.

The second step was to examine all the reflective statements on a specific topic to identify levels, and to project possible future levels that might be attained. While many of the schemes in reviewed studies seemed to have stipulated four levels a priori, we were content to let the type of reflection determine the number and description of levels. The five categories above each yielded either three or four levels. While the levels are unique to each category, a common theme does run through them:

- Level one segments are descriptions only, or descriptions with brief or vague comments, but no discernable reflection.

- By level two and descriptions and comments have explanations, reasons or possible causes. Brief suggestions leading might also be offered at this level.

- By level three comments are insightful, including an indication of the significance of the comment. Suggestions are concrete and action oriented.

- By level four comments and suggestions are linked to recognized good practices, overall curriculum goals, or theories.

At the end of these two steps we had the first draft of an instrument designed to gauge categories and levels of post-lesson discussion sessions. The third step was for each of the three authors to independently apply the categories and levels to the South African and Indonesian transcripts, and to compare results. These were then used to refine the descriptions of the categories and levels. Segments where our codings were not in agreement were analyzed and changes made to the category and level descriptors.

In the fourth and final step, the revised descriptors were used to code the discussion segments of the Kenyan and Japanese transcripts. Again each author coded the segments independently, and the results were compared and used to once more sharpen the category and descriptor levels, and to provide examples.

\section{Instrument Developed}

The product of the procedure described above second round of analysis can be found in Table One. The instrument comprises five categories which encompass the topics found in the transcripts of the reflection sessions analyzed. The comments under each of these topics may be further categorized into three or four levels of reflection. The instrument provides 
descriptors for each of the topics and levels in a five by four matrix (see Table one).

The procedure also led to the development of a coding manual, which is available at www.naruto-u.ac.jp/facultystaff/onoy/. This manual provides suggestions and example on how to segment the discussion into single idea "chunks". It goes on to flesh out the descriptors shown in Table 1 in greater detail and provides and examples for each category at each level. Finally it gives some suggestions on how a team or researchers might go about coding the segmented comments made during a post-lesson reflection session.

Table 1: Categories and Levels of the Instrument Designed to Measure Post-lesson Reflection

\begin{tabular}{|c|c|c|c|c|c|}
\hline $\begin{array}{l}\text { L } \\
\text { E } \\
V \\
\text { E } \\
\text { L }\end{array}$ & $\begin{array}{l}\text { Teaching and } \\
\text { learning strategies; } \\
\text { Instructional } \\
\text { techniques and } \\
\text { practices }\end{array}$ & $\begin{array}{l}\text { Teacher behavior; } \\
\text { teacher } \\
\text { characteristics; } \\
\text { communication skills }\end{array}$ & $\begin{array}{l}\text { Lesson as } \\
\text { experienced by } \\
\text { students; student } \\
\text { learning; student } \\
\text { behavior; interaction } \\
\text { between students }\end{array}$ & $\begin{array}{l}\text { Achievement of } \\
\text { lesson and } \\
\text { curriculum } \\
\text { objectives (e.g. } \\
\text { thinking skills, } \\
\text { creativity, } \\
\text { conceptual } \\
\text { understanding); } \\
\text { inconsistency } \\
\text { with objectives }\end{array}$ & $\begin{array}{l}\text { Logistics; } \\
\text { management; } \\
\text { planning; use } \\
\text { of materials } \\
\text { and teaching } \\
\text { aids }\end{array}$ \\
\hline 1 & $\begin{array}{l}\text { * Descriptions of } \\
\text { strategy or practice } \\
\text { without a comment or } \\
\text { suggestion. This } \\
\text { includes long, detailed } \\
\text { descriptions. } \\
\text { * Comments } \\
\text { concerning positive or } \\
\text { negative aspects of } \\
\text { instruction, but which } \\
\text { are superficial and/or } \\
\text { vague. This includes } \\
\text { value statements } \\
\text { tagged onto a } \\
\text { description. }\end{array}$ & $\begin{array}{l}\text { *Descriptions of teacher } \\
\text { behavior and/or } \\
\text { characteristics without a } \\
\text { comment or suggestion. } \\
\text { This includes long, } \\
\text { detailed descriptions. } \\
\text { * Comments concerning } \\
\text { positive or negative } \\
\text { aspects of the teacher, } \\
\text { but which are } \\
\text { superficial and/or } \\
\text { vague. This includes } \\
\text { value statements tagged } \\
\text { onto a description. }\end{array}$ & $\begin{array}{l}\text { * Descriptions of } \\
\text { student } \\
\text { experience/behavior } \\
\text { without a comment or } \\
\text { suggestion. This } \\
\text { includes long, detailed } \\
\text { descriptions. } \\
\text { * Comments } \\
\text { concerning positive or } \\
\text { negative aspects of } \\
\text { student } \\
\text { experience/behavior } \\
\text { are superficial and/or } \\
\text { vague. This includes } \\
\text { value statements } \\
\text { tagged onto a } \\
\text { description. }\end{array}$ & $\begin{array}{l}\text { * Claim of } \\
\text { achievement } \\
\text { without comment, } \\
\text { or if comment is } \\
\text { present it is trivial } \\
\text { and/or vague. }\end{array}$ & $\begin{array}{l}\text { * Descriptions } \\
\text { of action } \\
\text { without } \\
\text { comment, or } \\
\text { with brief } \\
\text { tagged on } \\
\text { comment. } \\
\text { * Comments } \\
\text { concerning } \\
\text { positive or } \\
\text { negative aspects } \\
\text { of the action are } \\
\text { trivial and/or } \\
\text { vague. }\end{array}$ \\
\hline 2 & $\begin{array}{l}\text { * Descriptions of } \\
\text { strategy or practice } \\
\text { which includes an } \\
\text { explanation, a reason } \\
\text { or possible cause for } \\
\text { the observation. } \\
\text { * Comments (positive } \\
\text { and negative) are } \\
\text { focused on non-trivial } \\
\text { aspects of instruction, }\end{array}$ & $\begin{array}{l}\text { * Descriptions of } \\
\text { teacher behavior and/or } \\
\text { characteristics which } \\
\text { includes an explanation, } \\
\text { a reason or possible } \\
\text { cause for the } \\
\text { observation. } \\
\text { * Comments (positive } \\
\text { and negative) are } \\
\text { focused on non-trivial }\end{array}$ & $\begin{array}{l}\text { * Descriptions of } \\
\text { student } \\
\text { experience/behavior } \\
\text { which include an } \\
\text { explanation, a reason } \\
\text { or possible cause for } \\
\text { the observation. } \\
\text { * Comments (positive } \\
\text { and negative) are } \\
\text { focused on non-trivial }\end{array}$ & $\begin{array}{l}\text { * Comments on } \\
\text { achievement, or } \\
\text { lack thereof, are } \\
\text { focused on } \\
\text { non-trivial aspects } \\
\text { of the goal. } \\
\text { However, } \\
\text { suggestions } \\
\text { pertaining to } \\
\text { achieving the goal }\end{array}$ & $\begin{array}{l}\text { * Comments } \\
\text { (positive and } \\
\text { negative) are } \\
\text { focused on } \\
\text { non-trivial } \\
\text { aspects, but are } \\
\text { not specific. } \\
\text { * Suggestions } \\
\text { are not specific } \\
\text { and are not }\end{array}$ \\
\hline
\end{tabular}


but are not specific.

* Suggestions

pertaining to

improving teaching

strategies or

instruction are not

specific or detailed.

Also these

suggestions are not

backed up with a

rationale or expected

outcome.

* Comments (positive

and negative) on

instruction are

insightful, including

an indication of the

significance of the

comment.

* Suggestions are concrete and action

oriented, pertaining to

improving the quality

and extent of learning/

teaching strategies,

use of materials, etc.

They need to be

backed with a

rationale or expected

outcome.

* Comments and/or

suggestions are linked

to recognized good

practices, overall

curriculum goals,

4 and/or theories. They

are made in relation to

a wider context. aspects of teacher

behavior and/or

characteristics but are

not specific.

* Suggestions

pertaining to improving

teacher behavior and/or

characteristics are not

specific or detailed.

Also these suggestions

are not backed up with a

rationale or expected

outcome.

* Comments (positive

and negative) on the

teacher behavior and/or

characteristics are

insightful, including an

explanation and/or an

indication of the

significance of the

comment.

* Suggestions are

concrete and action

oriented pertaining to

improving the quality of

the teacher behavior

and/or characteristics.

They need to be backed

with a rationale or

expected outcome. aspects of student

experience/behavior

but are not specific.

* Suggestions

pertaining to

improving student

experience/behavior

are not specific or

detailed. Also these

suggestions are not

backed up with a

rationale or expected

outcome.

* Comments (positive and negative) on

student

experience/behavior

are insightful,

including an

explanation and/or an

indication of the

significance of the

comment.

* Suggestions are

concrete and action

oriented pertaining to

improving the quality

of the student

experience/behavior.

They need to be

backed with a

rationale or expected

outcome.

* Comments (positive and negative) and/or

suggestions are linked

to recognized good

practices, overall

curriculum goals,

and/or theories. They

are made in relation to

a wider context. are absent or not

specific.

backed up with

a rationale or

expected

outcome.

$\begin{array}{ll}\text { * Comments on } & \text { *Comments } \\ \text { achievement, or } & \text { (positive and } \\ \text { lack thereof, are } & \text { negative) are } \\ \text { insightful. } & \text { insightful, } \\ \text { Suggestions are } & \text { including an } \\ \text { concrete and } & \text { explanation } \\ \text { action oriented } & \text { and/or an } \\ \text { pertaining to } & \text { indication of the } \\ \text { achieving the } & \text { significance of } \\ \text { goal. } & \text { the comment. } \\ & * \text { Suggestions } \\ & \text { are concrete, } \\ & \text { action oriented. } \\ & \text { They need to be } \\ & \text { backed with a } \\ & \text { rationale or } \\ & \text { expected } \\ & \text { outcome. }\end{array}$

* Comments

and/or

suggestions are

linked to

recognized good

practices, overall

curriculum goals,

and/or theories.

They are made in

relation to a wider

context. 


\section{Application}

In order to establish the usefulness and sensitivity of the instrument, the final version was used to code the post-lesson discussion session undertaken by teachers in a middle school in Indonesia. This analysis was then compared with the observation notes and intuitive impressions that the first author noted when she observed the lesson and participated in the following post lesson session (Ono, 2010).

The transcript was divided into segments using the same procedure as used in the development of the instrument. Each of the three authors then coded the segments and supplied an explanation for his or her choice. Where the coding differed, it was left to the first author to carefully read the explanations and to make the final decision on the category and level. However in most cases the three authors were in full agreement. The overall results are given in Table 2 and Table 3.

Table 2: Percentage of Discussion Segments per Category

\begin{tabular}{lcc}
\hline Category and its description & $\begin{array}{l}\text { Post-lesson reflection } \\
\text { comments }\end{array}$ \\
\hline $\begin{array}{l}\text { A: Teaching and learning strategies; Instructional techniques } \\
\text { and practices }\end{array}$ & 8 & $18.6 \%$ \\
B: Teacher behavior; teacher characteristics; communication \\
$\quad$ skills \\
$\begin{array}{l}\text { C: Lesson as experienced by students; student behavior; } \\
\quad \text { interaction between students }\end{array}$ \\
$\begin{array}{l}\text { D: Achievement of lesson and curriculum objectives; } \\
\quad \text { inconsistency with objectives }\end{array}$ \\
$\begin{array}{l}\text { E: Logistics; management; planning; use of materials and } \\
\text { teaching aids }\end{array}$ \\
\hline Total
\end{tabular}

The analysis by category revealed that the comments in this case centered on three categories: namely "E: Logistics”, “C: Lesson as experienced by students”, and “A: Teaching and learning strategies". There were few comments whether the lesson had achieved the intended objective or not. Percentage of category may differ by the objective of a post lesson discussion (Chikamori et al, 2013). The levels of the comments remained relatively low (see Table 3). 
Table 3: Percentage of Discussion Segments per Level

Level and its description

Post-lesson reflection comments

One: Descriptions only, or descriptions with a very brief and vague comment.

Two: Comments and suggestions which are not specific.

29

$67.4 \%$

Three: Comments and suggestions which are more specific and deal with issues of greater significance.

Four: Comments and/or suggestions are linked to recognized good practices, overall curriculum goals, and/or theories.
13

0

$30.2 \%$

1

$2.3 \%$

Total

$\mathrm{N}=43$

$99.9 \%$

The predominance of the three categories and the low level of the discussion comments as revealed the analysis provided by the instrument supports the intuitive impressions of the first author (Ono, 2010). Hence the instrument can provide a more systematic, but nevertheless accurate, method of representing a post-lesson reflection discussion.

\section{Conclusion}

The implementation of lesson study and research on its effectiveness are experiencing a surge of international interest. The need for an instrument that can be used to gauge the level of reflection achieved when lesson study is practiced is apparent. We hope that this instrument will prove useful to researchers in the area of lesson study.

The ways in which we have begun to use this instrument may prove beneficial to other potential users. Lesson study is a cyclic process, where the goal is improved teaching and learning. We already have evidence that when lessons are refined through this process, improvements are made (Ono et al., 2011). A missing link in this research is whether and how the post-lesson reflection sessions contributed to this improvement. We are in the process of analyzing situations where the lesson study cycle has been completed at least twice to find out whether the quality of discussion increased over time, and how this may have contributed to changes in the lesson. We have also begun to use the instrument as an educational tool in workshops that we offer on the introduction of lesson study. Lesson analysis is one skill that is central in this endeavor. We have begun to use the instrument to rate lesson analyses, and to encourage participants to determine for themselves whether their own analyses improve with practice. Finally we see a potential use for the instrument in situations where participants in our workshops return to their own countries and implement lesson study. One finding of our research (Chikamori et al., 2013) suggests that the level and quality of post-lesson reflection is largely influenced by a small number of key participants, who set the tone for the rest of the group. Hence we anticipate using the instrument to facilitate the development of these pace-setters in the new groups that are formed in the host countries of the participants in our workshops.

The categories and levels, as described in Table 1, and elaborated on in the manual, should 
not be regarded as set in concrete. During the development process, as we turned our attention from one transcript to another, we found that category descriptions that were adequate for one situation did not quite fit the next, and modifications needed to be made. We suspect that as we continue to use the instrument, further modifications might be desirable. Hence we urge researchers who choose to use this instrument to be flexible and creative. Modify the categories and levels to best suit the context in which the research is undertaken.

\section{References}

Boud, D., Keogh, R., \& Walker, D. (1985). Promoting Reflection in Learning: A Model. In D. Boud, D., R. Keogh, \& D. Walker (Eds.), Reflection: Turning Experience into Learning (pp. 18-40). Kogan Page: London.

Chikamori, K., Ono, Y., \& Rogan, J.M. (2013). A lesson study approach to improving a biology lesson. African Journal of Research in Mathematics, Science and Technology Education (in press).

Dewey, J. (1933). How we think: A restatement of the relation of reflective thinking to the educative process. D.C. Heath and Company: New York.

Dinkelman, T. (2000). An Inquiry into the Development of Critical Reflection in Secondary Student Teachers. Teaching and Teacher Education, 16, 195-222. http://dx.doi.org/10.1016/S0742-051X(99)00055-4

Elliott, J. (2012). Developing a science of teaching through lesson study. International Journal for Lesson and Learning Studies, 1, 108-125. http://dx.doi.org/10.1108/20468251211224163

Fendler, L. (2003). Teacher Reflection in a Hall of Mirrors: Historical Influences and Political Reverberations. Educational Researcher, 32(3), 16-25. http://dx.doi.org/10.3102/0013189X032003016

Galvez-Martin, M.E., Bowman, C.L., \& Morrison, M.A. (1998), An Exploratory study of the level of reflection by preservice teachers. Mid-Western Educational Researcher, 11(2), 9-18.

Goodman, J. (1984). Reflection and teacher education: A case study and theoretical analysis. Interchange, 15(3), 9-26. http://dx.doi.org/10.1007/BF01807939

Hatton, N., \& Smith, D. (1995). Reflection in teacher education: Towards definition and implementation. Teaching and Teacher Education, 11, 33-49. http://dx.doi.org/10.1016/0742-051X(94)00012-U

Kember, D., McKay, J., Sinclair, K., \& Wong, F.K.Y. (2008). A four-category scheme for coding and assessing the level of reflection in written work. Assessment and Evaluation in Higher Education, 33, 369-379. http://dx.doi.org/10.1080/02602930701293355

King, P.M., \& Kitchener, K.S. (1994). Developing Reflective Judgment: Understanding and 
promoting intellectual growth and critical thinking in adolescents and adults. Jossey-Bass: San Francisco.

Latour, B. (1988). The politics of explanation. In S. Woolgar (Ed.), Knowledge and reflexivity: New frontiers in the sociology of knowledge (pp. 155-176). Sage: London.

Marcos, J. M., Sanchez, E., \& Tillema, H.H. (2011). Promoting teacher reflection: what is said to be done. Journal of Education for Teaching: International research and pedagogy, 37, 21-36. http://dx.doi.org/10.1080/02607476.2011.538269

Mezirow, J. (1998). On Critial Reflection. Adult Education Quarterly, 48, 185-198. http://dx.doi.org/10.1177/074171369804800305

Moon, J.A. (1999). Reflection in Learning and Professional Development. Kogan Page: London.

Ono, Y. (2010). Report on science lesson presentations by Japanese and Indonesian teachers in the third international conference on lesson study. Unpublished manuscript. Original in Japanese.

Ono, Y., Chikamori, K., \& Rogan, J.M (2011). Reflections on a mutual journey of discovery and growth based on a Japanese-South African collaboration. Professional Development in Education, 37, 335-352. http:// dx.doi.org.10.1080/19415257.2010.509980

Ross, D.D. (1989). First Steps in Developing a Reflective Approach. Journal of Teacher Education, 40(2), 22-30. http://dx. doi.org/10.1177/002248718904000205

Schön, D.A. (1983). The Reflective Practitioner: how Professionals think in Action. Basic Books: New York.

Suratno, T., \& Iskandar, S. (2010). Teacher reflection in Indonesia: Lessons learnt from a lesson study program. US-China Education Review, 7(12), 39-48. http://www.davidpublishing.org/show.html?6140

Suzuki, Y. (2012). Teachers’ professional discourse in a Japanese lesson study. International Journal for Lesson and Learning Studies, 1, $216 \quad-231$. http://dx.doi.org/10.1108/20468251211224163

Van Manen, M. (1991). Reflectivity and the Pedagogical Moment: the normativity of pedagogical thinking and acting. Journal of Curriculum Studies, 23, 507-536. http://dx.doi.org/ 10.1080/0022027910230602

Van Woerkom, M. (2003). Critical Reflection at Work. Bridging Individual and Organisational Learning. PhD thesis, University of Twente, Netherlands.

Ward, J.R., \& McCotter, S.S. (2004). Reflection as a visible outcome for preservice teachers. $\begin{array}{llll}\text { Teaching } \text { and } \quad \text { Teacher 243-257. } & \text { Education, }\end{array}$ http://dx.doi.org/10.1016/0742-051X(94)00012-U 


\section{Copyright Disclaimer}

Copyright reserved by the author(s).

This article is an open-access article distributed under the terms and conditions of the Creative Commons Attribution license (http://creativecommons.org/licenses/by/3.0/). 